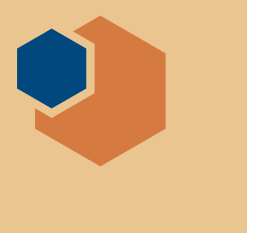

\title{
Materials research represented on US science advisory council
}

\section{whitehouse.gov/PCAST}

E arly last fall, the Biden administration announced 30 of the United States' most distinguished leaders in science and technology as members of his President's Council of Advisors on Science and Technology (PCAST). Among the members are scientists prominent in the field of materials research.

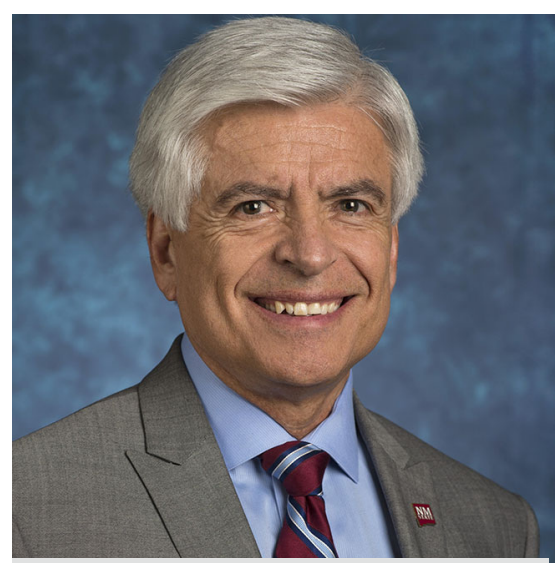

Dan E. Arvizu

Chancellor, New Mexico

State University System

Dan E. Arvizu, Chancellor of the New Mexico State University System, is an expert in energy materials, process sciences, and technology commercialization with over 30 years of experience in various roles at US Department of Energy (DOE) National Laboratories. He served as Director and Chief Executive of the National Renewable Energy Laboratory from 2005 to 2015 . Arvizu serves on a number of boards, panels, and advisory committees including the Singapore International Advisory Panel on Energy and the Stanford Precourt Institute for Energy Advisory Council.

"From COVID-19, to cyber security, to clean energy and other topics, science and technology are at the core of so many issues facing the US at this time," Arvizu said in a news release. "I'm humbled and honored that I can serve our country by providing my expertise."
John Banovetz is a chemist, materials scientist, and business leader with over 25 years' experience in corporate research and technology development, manufacturing, strategy, innovation, and environmental stewardship. He holds multiple patents in polymer science and adhesives, and oversees more than 8,000 researchers worldwide in his role as the Executive Vice President, Chief Technology Officer and Environmental Responsibility at 3M Company.

Laura H. Greene is Chief Scientist of the National High Magnetic Field Laboratory (at Florida State University, the University of Florida, and Los Alamos National Laboratory) and the Marie Krafft Professor of Physics at Florida State University. Her research focuses on quantum materials, focuses on fundamental studies utilizing novel materials growth with planar tunneling and point contact electron spectroscopies to elucidate the mechanisms of unconventional superconductivity.

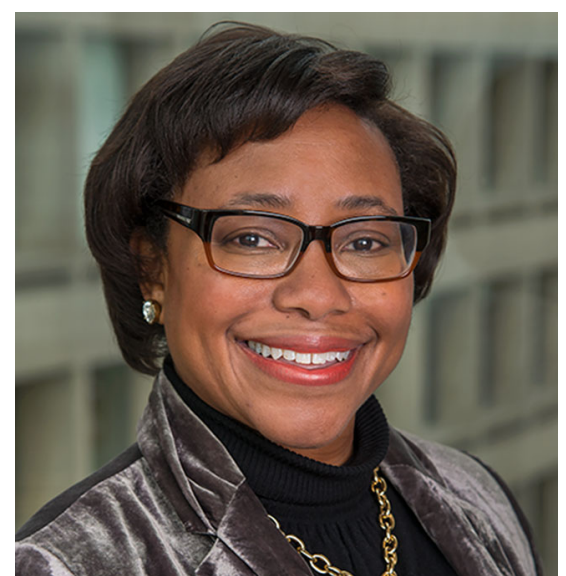

Paula T. Hammond

Massachusetts Institute of Technology

Paula T. Hammond of the Massachusetts Institute of Technology (MIT) — and the 2019 recipient of the
David Turnbull Lectureship from the Materials Research Society-is a leading researcher in how to use polymers, nanotechnology, and biomaterials to improve human health. In her past work, she has designed polymers to improve batteries, solar cells, and alternative fuel cells. Hammond is Head of MIT's Department of Chemical Engineering and an Institute Professor and member of the Koch Institute for Integrative Cancer Research at MIT.

"For me, this is an exciting opportunity," Hammond said in a news release. "I have always been interested in considering how science can solve important problems in our community, in our country, and globally. It's very meaningful for me to have a chance to have an advisory role at that level."

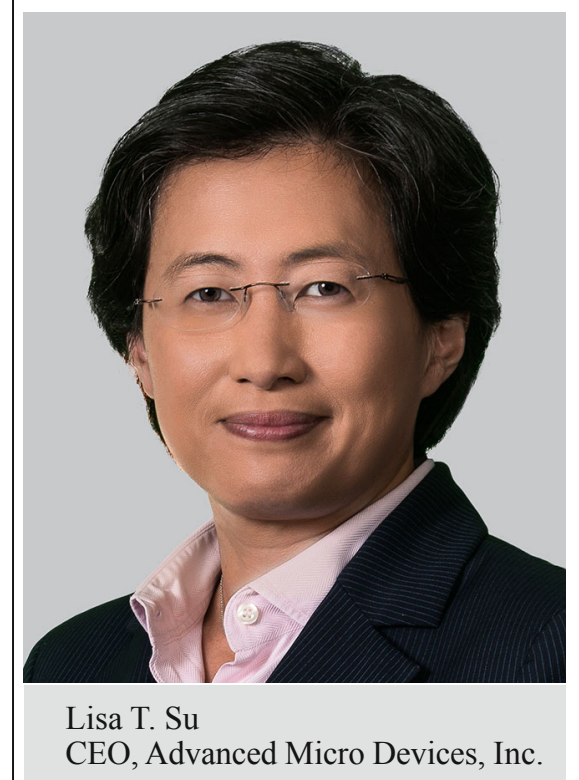

Lisa T. Su is an expert in semiconductor devices and high-performance processors. She pioneered new ways to connect computer chips using copper instead of aluminum, resulting in $20 \%$ faster chip speeds. She is President and 
CEO of the semiconductor and microprocessor company Advanced Micro Devices, Inc. (AMD). Fortune Magazine named $\mathrm{Su}$ the \#2 "Business Person of the Year" for 2020 and she is one of Barron's "World's Best CEOs" of 2019. She currently serves on the Board of Directors of Cisco Systems, Inc.; the US Semiconductor Industry Association; and the Global Semiconductor Alliance.

"Honored to be named to the US President's Council of Advisors on Science and Technology (PCAST) to work with an amazing group of people on important issues impacting our nation," Su tweeted.

PCAST is the sole body of external advisors charged with making science, technology, and innovation policy recommendations to the president and the White House. PCAST Co-chair and Director of the White House Office of Science and Technology Policy Eric Lander said in a news release, "President
Biden understands that addressing the opportunities and challenges we faceto our health, our planet, our economic prosperity, and our national securitywill require harnessing the full power of science and technology."

"Science and technology permeate so many elements of government decision making," said PCAST Co-chair Maria T. Zuber, in a news release. "I am excited to bring this historic and brilliant group's knowledge, experience, and innovative thinking to bear on the nation's toughest challenges in science and technology and navigate an equitable and inclusive path forward for the nation."

Lander, Zuber, and PCAST Cochair Frances Arnold lead a council of 27 members including 20 elected members of the National Academies of Sciences, Engineering, and Medicine; five MacArthur "Genius" Fellows; two former Cabinet secretaries; and two Nobel laureates. Its members include experts in materials science, astrophysics and agriculture, biochemistry and computer engineering, ecology and entrepreneurship, immunology and nanotechnology, neuroscience and national security, and social science and cybersecurity.

Furthermore, PCAST reflects the president's commitment to build an administration that reflects the face of the United States: women make up half of PCAST, and people of color and immigrants make up more than onethird of PCAST. Its diversity, according to the White House news release, will help the council bring to bear a wide range of perspectives to address the country's most pressing opportunities and challenges, so that science, technology, and engineering benefits the vast US population.

The full list of PCAST members and biographies can be accessed at white house.gov/PCAST.

Judy Meiksin

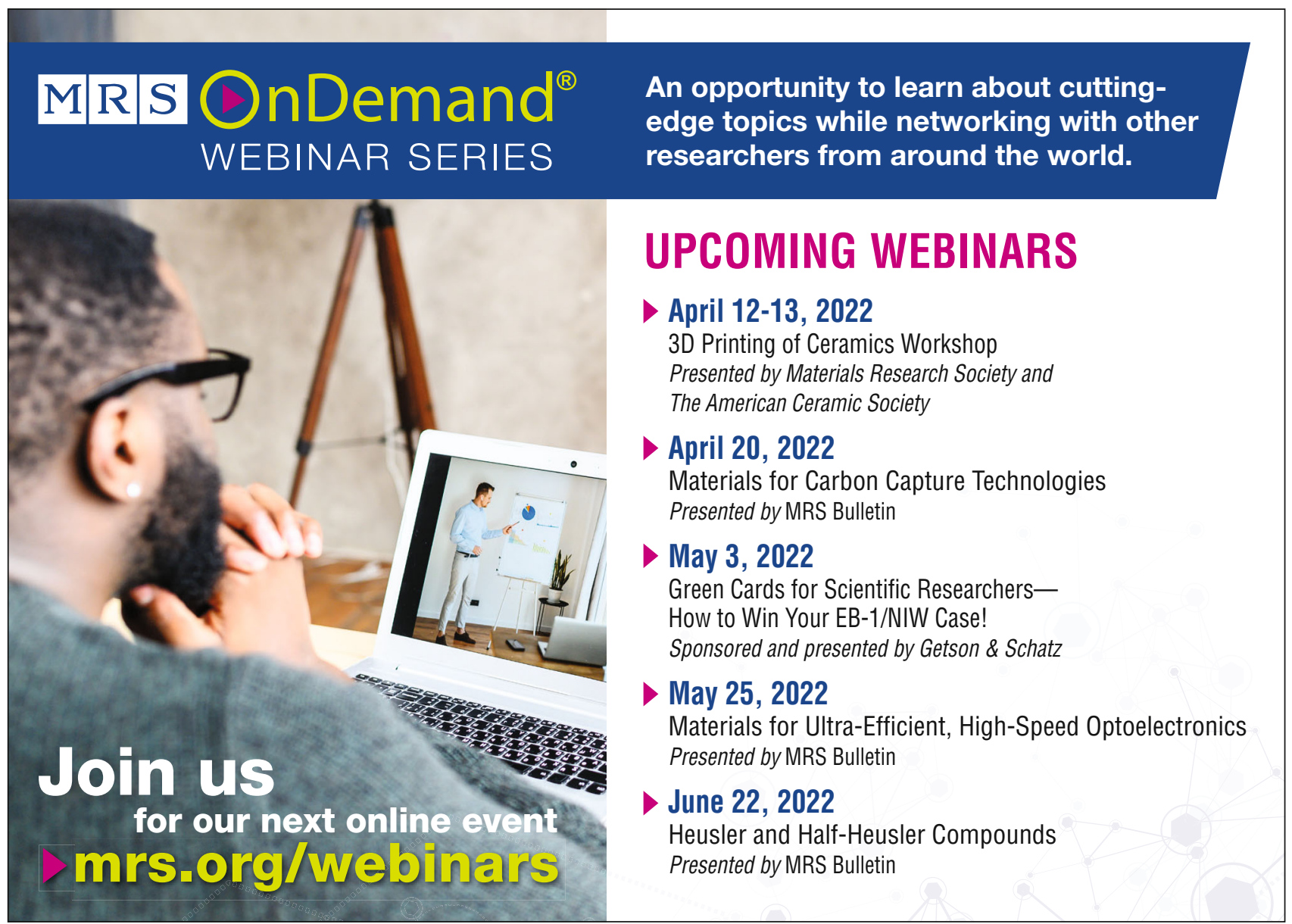

